\title{
The Role of Utilitarian, Brand value, Aesthetic, and the Cultural Factors on the Intention to Repurchase Smart Phones of Apple
}

\section{(Case Study among Students of Islamic Azad University Tehran Central Branch, Faculty of Management)}

\author{
Iran Farajzadeh ${ }^{1}$, Abdullah Naami ${ }^{2}$, Esfandiar Doshmanziari ${ }^{3}$ \\ ${ }^{1}$ M.A of Business Administration- International Commerce, Islamic Azad University of Tehran central branch, \\ Iran \\ ${ }^{2} \mathrm{PhD}$, Lecturer at Central Branch of Islamic Azad University of Tehran, Iran \\ ${ }^{3}$ Assistant Prof., Faculty of Management and Accounting, Islamic Azad University, Islamshahr, Iran \\ Correspondence: Iran Farajzadeh, M.A of Business Administration- International Commerce, Islamic Azad \\ University of Tehran central branch, Iran
}

Received: September 25, 2018

Accepted: January 31, 2019

Online Published: February 11, 2019

doi:10.5539/ibr.v12n3p101

URL: https://doi.org/10.5539/ibr.v12n3p101

\begin{abstract}
Today, in the highly competitive world of business, having loyal customers is a valuable asset for businesses and companies. In the same vein, the re-purchase intention plays a vital role and identifying and improving its influential factors can boost this valuable asset. Therefore, the main objective of the present study is to study the role of utilitarian, brand value, aesthetic, and the cultural factors on the intention to re-purchase Apple smartphones. This study is applied and has a descriptive-correlative design. The statistical population consisted of approximately 6000 students of management at the Central Branch of Tehran Azad University. The sample size was calculated 361 people using Morgan table. The simple random sampling method used. To test the research hypothesis, structural equation modeling (SEM) by Lisrel has been used. The findings show that product's design, perceived quality, subjective norms and brand popularity were the factors that have had a positive effect both directly and through the intermediary variable of socio-cultural reputation on the intention to repurchase this product.
\end{abstract}

Keywords: re-purchase intention, design appeal, perceived quality, subjective norms, brand popularity, socio-cultural image

\section{Introduction}

In recent years, organizations have undergone major changes due to the sharp growth of economic competition and dynamics. In today's competitive market, many organizations are losing their customers, however this loss does not mean losing customers' needs. Instead, other resources are catering for their needs. In the past, attracting new customers had been the main strategy of the organizations, but today the business policy of organizations focused on maintaining their customers. Since businesses cannot survive without customers, the re-purchase intention of customers has come to the fore of managers' attention, giving rise to the notion of customer relationship management (Fariabi et al., 2011).

Among the various goods and services, smartphones has become now an indispensable necessity for the majority of people (Persaud \& Azhar, 2012). These types of cellphones are use by many consumers for a variety of purposes, such as conversation, social networks, emails, finance, shopping, etc. Despite the growing use of this product among different consumers, few studies have been conducted on the factors which influence its purchasing decision and the intention to re-purchase it (Kim, Chun, \& Lee, 2010; Koo, Chung, \& Kim, 2015). There are studies on the re-purchase intention among Iranian consumers, however none have studied smartphones. For instance, Amini Lari and Ebrahimifard (2016) examined the effect of perceived quality of services on repurchase intention via the mediating role of communication quality. Furthermore, Wang et al. (2012) also examined the impact of product images on repurchase intention. Pendragast et al. investigated the 
impact of experience of a product on repurchase intention.

Most of these studies have examined the impact of one or more limited factors on purchase intention, while the customer purchase decision-making is a complicated process, which involves a variety of factors. In addition, a review of the existing literature shows that there is a gap of research on the factors affecting the repurchase intention of smartphones in Iran. Most of the studies conducted in Iran examine the effect of satisfaction, customers' loyalty and brand dimensions on repurchase intention, and the impact of other variables such as product design, perceived quality, subjective norms, brand popularity, and social reputation of brand are unclear on repurchase intention.

Therefore, to fill this gap, the present study seeks to re-test a previously presented model. This model presented in the study of Filieri and Lin (2017) and will be reexamine here in another statistical population considering the role of utilitarian, brand value, aesthetics and cultural factors in the repurchase intention of Apple smartphones.

\section{Review of Literature}

\subsection{Theoretical Background}

Today, organizations have come to this belief that long-term profitability is only achieved via customers' repurchase. Therefore, they keep trying to further facilitate the purchase process for consumers. The repurchase intention refers to consumers' repeated purchases of a specific brand after using that brand or the customer's belief in continuing to buy from a specific company in the future (Schoefer \& Diamantopoulos, 2008).

The repurchase intention refers to a motivation in customers to repeat their purchasing behavior, which is also known as the result of perceived value of the product or service brand. The re-purchase intention is a behavior relying on cognition and emotion (Schofer \& Diamantopoulos, 2008) and, as most researchers stated, re-purchase intention is the behavioral index of the customers' loyalty (Ha, Muthaly, \& Akamavi, 2010) and the main outcome of customer satisfaction (Quintal \& Polczyncki, 2010). Studies show that repurchase intention depends essentially on the number of purchases (East, Wright, \& Vanhuele, 2008) and customer purchase quantity (Blackwell, Miniard, \& Engel, 2001).

In marketing management, the importance given to repurchase is evident, since customer retention requires less resources rather than attracting new customers and this is economically acceptable. The repurchase intention is a factor affecting the future customer-company relationship, the profitability of the company and its success (Teimourpour. Heidarzadeh Hanzaee, 2011).

In general, there are two perspectives related to the repurchase intention: an arbitrary and a definitive repurchase view. In the arbitrary view, repurchase happens completely accidentally, while in a definitive purchase, purchases made based on satisfaction from previous experiences, in other words, brand loyalty (Kuo, Wu, \& Deng, 2009).

\subsection{The Factors Affecting on Customers'Loyalty and Repurchase Intention}

Many studies on the value-loyalty relationship pointed to the direct impact of value on repurchase intention (Kuo, Wu, \& Deng, 2009). Meanwhile, it should be considered that customer value leads to customer satisfaction, followed by loyalty. Similarly, more emphasis placed on customer satisfaction than customer value, since satisfaction directly affects loyalty and not value. This relation leads to repurchase intention, which is a process of individual selection of goods or services from the same company, and primarily based on former purchase experiences (Qian, Peiji, \& Quanfu, 2011). However, in another perspective, customer satisfaction is the forerunner of brand loyalty and created after a process, which is the result of customer's assessment of the brand or product and the key factor in the decision to re-purchase. Of course, it should be noted that satisfaction is a necessary-but not enough - condition for loyalty (Agustin \& Singh, 2005). On the other hand, trust and commitment can be considered as factors influencing loyalty, by which consumers show their trust in a brand based on the positive beliefs derived from their experiences with the company's behavior and product function (Ashley \& Leonard, 2009). Since trust creates a strong bond between the brand and the customer, it is one of the factors determining brand loyalty. (Morgan \& Hunt, 1994)

\subsection{Conceptual Model of Research}

As stated in the introduction, the present study is aimed to use the model of Filieri and Lin (2017) to examine the effective factors on the repurchase intention of Apple's smartphones among Iranian students. Accordingly, the conceptual model of the research presented in Figure 1. The practical definitions of the variables in this model provided in the following (Filieri and Lin, 2017):

- Design Appeal: Selection of a set of aesthetic factors by the design team and combining them to create a special sense for the customer. 
- Perceived Quality: The quality perceived by the customer in terms of features such as durability, reliability, and performance.

- Subjective Norms: Individuals 'behaviors against social pressures and others' influence.

- Brand popularity: the degree to which the consumer expresses his/her interest in a brand compared to the other rival brands.

- Social image: A set of values that people are looking for by using Apple phones; values such as being specific, proudness, and arrogance.

- Repurchase intention: The probability that the customer will purchase the same product the next time after experiencing it.

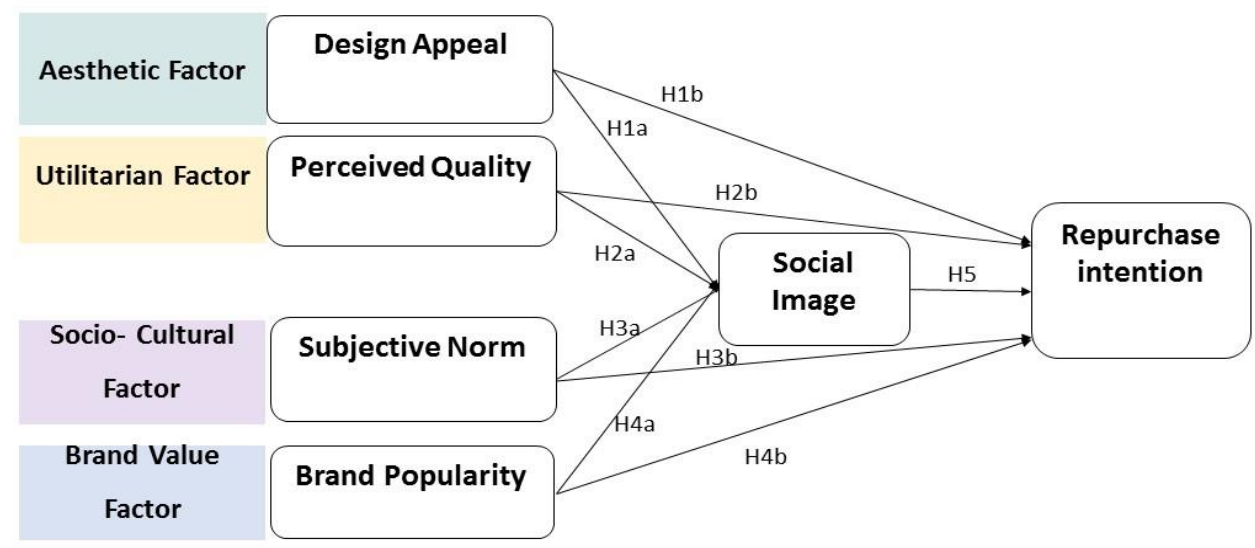

CHART1. Theoretical model and hypothesized relationships

(Filieri and Lin (2017))

According to the proposed model, the following hypotheses are developed:

1. The design of Apple phones has a significant impact on the socio image.

2. The design of Apple phones has a significant impact on the intention to repurchase Apple phones.

3. Perceived quality has a significant impact on the socio image.

4. Perceived quality has a significant impact on the intention to repurchase Apple phones.

5. The subjective norms have a significant impact on the socio image.

6. The subjective norms have a significant impact on the intention to repurchase the Apple phones.

7. Brand popularity has a significant impact on the socio image.

8. Brand popularity has a significant effect on the intention to repurchase Apple phones.

9. The socio image has a significant impact on the intention to repurchase Apple phones.

\section{Method}

The present study is an analytical-descriptive research in terms of design, and applied in terms of purpose. Data collection was done from the documents and sources available in the libraries. Given that a questionnaire was used to collect the research data, the present study is a survey. The statistical population of the study included all students of management at the central branch of Azad university of Tehran, including about 6000 people. The sample size was determined $n=361$ according to the Morgan table. To evaluate the normality of the data, the kolmogorov-smirnov test was used. In order to test the research hypothesis, the structural equation in Lisrel was employed. 


\section{Results}

Cronbach's alpha coefficient was calcualted to assess the reliability of questionnaire. Table 1 shows the Cronbach's alpha coefficient for the variables of study.

Table 1. Variables, number of questions and reliability coefficient

\begin{tabular}{ccc}
\hline Variable & N of questions & Cronbach's alpha \\
\hline Sociocultural factors & 6 & 0.874 \\
Design appeal & 6 & 0.864 \\
Subjective norm & 6 & 0.807 \\
Brand popularity & 4 & 0.712 \\
Perceived quality & 4 & 0.882 \\
Repurchase intention & 4 & 0.920 \\
Total questionnaire & 30 & 0.926 \\
\hline
\end{tabular}

Using SPSS statistical software for data analysis, Cronbach's alpha coefficient for the total questionnaire was determined 926, which was desirable.

\section{Normality of data test}

The assumption of the normality of the data tested via Kolmogorov-Smirnov technique at a significance level of $5 \%$. Based on the results provided in Table 2, the research data are normal.

Table 2. Normality test

\begin{tabular}{ccc}
\hline Test construct & & Kolmogorov-Smirnov \\
\cline { 2 - 3 } & $\mathrm{Z}$ & Sig. \\
Design appeal & 0.717 & 0.682 \\
Subjective norm & 0.678 & 0.748 \\
Brand popularity & 0.583 & 0.887 \\
Perceived quality & 0.637 & 0.811 \\
Socio image & 0.431 & 0.992 \\
Repurchase intention & 0.686 & 0.734 \\
\hline
\end{tabular}

\section{Introducing Variables' Symbols}

In Table 3, the concepts and research factors along with their equivalents are provided.

Table 3. Concepts and research factors along with their equivalents in the model

\begin{tabular}{cc}
\hline Variable & Equivalent \\
\hline Design appeal & $\mathrm{X} 1$ \\
Subjective norm & $\mathrm{X} 2$ \\
Brand popularity & $\mathrm{X} 3$ \\
Perceived quality & $\mathrm{X} 4$ \\
Socio image & $\mathrm{Y}$ \\
Repurchase intention & $\mathrm{Z}$ \\
\hline
\end{tabular}

\section{Testing the research hypotheses}

To test the research hypotheses, structural equation modeling (SEM) is used. SEM is a comprehensive statistical approach to test the hypotheses about the relationships between observed and latent variables. For this purpose, the maximum likelihood method in LISREL has been used for estimation. In order to examine the research model which includes four independent variables (design appeal, subjective norms, brand popularity and perceived quality), it is necessary to ensure the fitness of the model before verifying structural relationships. In the research model, the quantity of chi-square has a degree of freedom of 185, which is desirable. Also, RMSEA is 0.017 and the Comparative Factor Index (CFI), Incremental Fitness Index (IFI), Normative Fitness Index (NFI), and Non-Normalized Fitness Index (NNFI) are all more than 0.9, so the model has an excellent fit (Table 4 )

Table 4. Goodness of fit

\begin{tabular}{cccccc}
\hline Index of fitness & RMSEA & CFI & NFI & NNFI & IFI \\
\hline Acceptable values & $0,08 \geq$ & $>0,9$ & $>0.9$ & $>0,9$ & $1-0$ \\
Estimated values & 0,017 & 0,96 & 0.91 & 0,91 & 0,92 \\
\hline
\end{tabular}

Figures 1 and 2 show the $t$-values and standardized estimates of the structural equation models for the conceptual model of research based on the relationship between independent variables and dependent variables. 


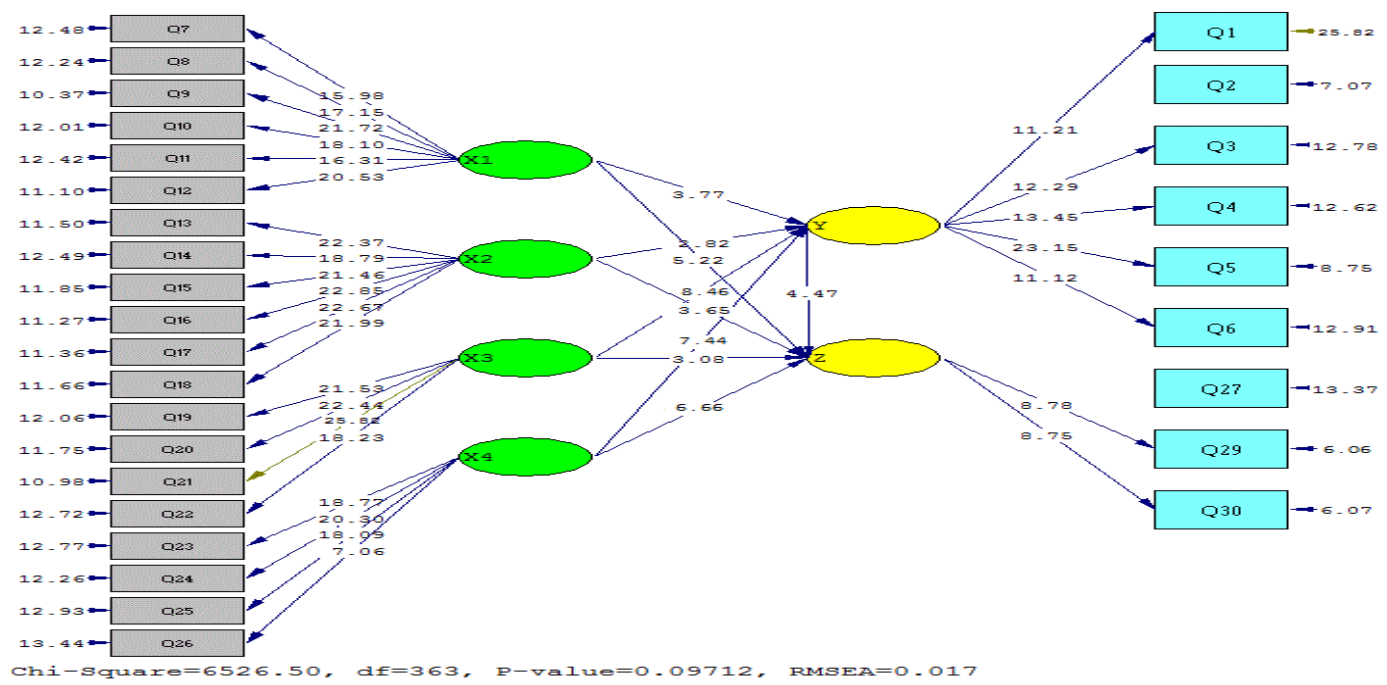

Figure 1. Model of the research in standard mode

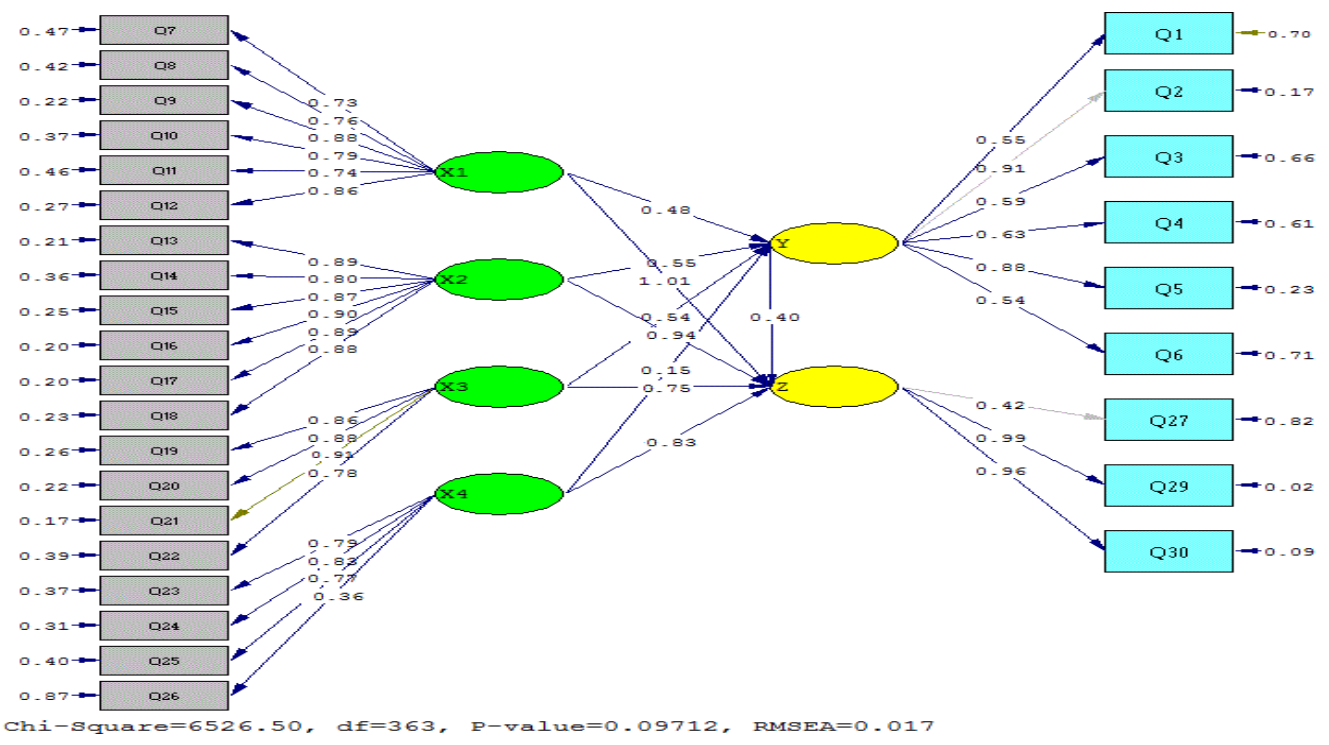

Figure 2. Model of the research in significance mode (T-VALUE)

The answer to research hypotheses is provided in table 5, based on figures 1 and 2 .

Table 5. The results of estimated model at sig level 0.05

\begin{tabular}{|c|c|c|c|}
\hline Hypotheses & T value & Standard coefficient & results \\
\hline The design of Apple phones has a significant impact on the socio image. & 3.77 & 0.48 & confirmed \\
\hline $\begin{array}{l}\text { The design of Apple phones has a significant impact on the intention to } \\
\text { repurchase Apple phones The design of Apple phones has a significant } \\
\text { impact on the intention to repurchase Apple phones }\end{array}$ & 5.22 & 1.01 & confirmed \\
\hline Perceived quality has a significant impact on the socio image. & 2.82 & 0.55 & confirmed \\
\hline $\begin{array}{l}\text { Perceived quality has a significant impact on the intention to repurchase } \\
\text { Apple phones. }\end{array}$ & 3.65 & 0.94 & confirmed \\
\hline $\begin{array}{l}\text { Perceived quality has a significant impact on the intention to repurchase } \\
\text { Apple phones }\end{array}$ & 8.46 & 0.54 & confirmed \\
\hline The subjective norms have a significant impact on the socio image. & 3.08 & 0.75 & confirmed \\
\hline $\begin{array}{l}\text { The subjective norms have a significant impact on the intention to } \\
\text { repurchase the Apple phones. }\end{array}$ & 7.44 & 0.15 & confirmed \\
\hline $\begin{array}{l}\text { Brand popularity has a significant effect on the intention to repurchase } \\
\text { Apple phones. }\end{array}$ & 6.66 & 0.83 & confirmed \\
\hline $\begin{array}{l}\text { The socio image has a significant impact on the intention to repurchase } \\
\text { Apple phones. }\end{array}$ & 4.74 & 0.40 & confirmed \\
\hline
\end{tabular}


Table 6. Path analysis

$\begin{array}{ll}\text { Design appeal } \rightarrow \text { sociocultural image } \rightarrow \text { repurchase intention } & 0.48 * 0.40=0.19 \\ \text { Subjective norms } \rightarrow \text { sociocultural image } \rightarrow \text { repurchase intention } & 0.55 * 0.40=0.22 \\ \text { Brand popularity } \rightarrow \text { sociocultural image } \rightarrow \text { repurchase intention } & 0.54 * 0.40=0.21 \\ \text { Perceived quality } \rightarrow \text { sociocultural image } \rightarrow \text { repurchase intention } & 0.15 * 0.40=0.06\end{array}$

As observed in the conceptual model, the effect of four independent variables (design appeal, subjective norms, brand popularity and perceived quality) on the repurchase intention as the dependent variable was investigated. Examining these four factors has been done both directly (hypotheses 2, 4, 6 and 8), and indirectly through the mediating role of the "sociocultural image" (variables 1,3,5, and 7). The results of the direct impact of the four factors are provided in Table 5. Table 6 also shows the results of analyzed data related to these effects by considering the mediating role of the "socio- cultural image".

Based on the findings provided in Table 5, all four independent variables had a positive and significant effect on the repurchase intention of customers because their significance level was more than 1.96. According to Table 6, these four factors can also have a positive impact on the repurchase intention of Apple smartphones in the statistical population by strengthening the "socio-cultural image" of brand in the consumers. This effect is related to the variables, respectively.

\section{Discussion}

The present study addresses one of the important issues in the domain of customer behavior, namely, the repurchase intention, and, by re-examination of a conceptual model (Filieri and Lin, 2017), the role of the four main factors underlying the intention to repurchase Apple smartphones is investigated. These factors include design appeal, subjective norms, brand popularity, and perceived quality. In addition, the indirect impact of these factors has been examined by considering the mediating role of the "socio-cultural image". The results of the research showed that these four factors, either directly or indirectly, have a positive significant effect on the customers' repurchase intention. The findings of this study are in line with the results of the study by Filieri and Lin (2017).

The importance of product design appeal in re-purchasing comes from the fact that the product's core capabilities play a crucial role in the consumer's decision to purchase it. These capabilities include both the ability to meet the needs of the consumer from a smartphone and its aesthetic aspects. Consequently, if smartphone manufacturers are constantly looking for updates and innovations in their design and style, they can have a positive effect on their customers' intention to repurchase their products.

The positive impact of perceived quality on repurchase intention can indicate the high price of the product, improving the sense of respect, prestige and social status of the individual. Possessing these positive feelings will create motivation in the customer to repurchase the same brand of smartphones.

The positive impact of brand popularity on repurchase intention can be explained by the fact that brand popularity in the community is a kind of attitude and perception of the brand that can extend to the consumers of that particular brand. Moreover, the social impact of using a smartphone with a specific brand by culture-oriented people can also be a source of personal interest and, consequently, an incentive to repurchase the same brand of smartphone.

Regarding the positive impact of subjective norms on the intention to repurchase Apple smartphones, it can be said that in societies with a collective culture such as Iran, tendency to consistent and conformity with other people is high, and hence the popularity of this type of smartphone makes consumers more likely to have something that is considered by others to be good, high quality, and have a high social image.

In this study, the variables which have a positive effect on the repurchase intention were identified, which were ignored in previous studies in Iran. It is suggested that in marketing research, the variables identified in this research including product design appeal, perceived quality, subjective norms, brand popularity and cultural-social image receive a special attention. According to the obtained coefficients, the design appeal has the highest impact on the repurchase intention of smartphones. So paying attention to this variable is very important for attracting customers. Subjective norms, perceived quality, brand popularity, and sociocultural image are the next priorities. Obviously, the present study is conducted for a foreign product. It is suggested to the future studies replicate this study with a domestic product, to identify the factors influencing the repurchase intention of domestic products and give a report to the manufacturer.

\section{References}

Agustin, C., \& Singh, J. (2005). Curvilinear effects of consumer loyalty determinants in relational exchanges. 
Journal of marketing research, 42(1), 96-108. https://doi.org/10.1509/jmkr.42.1.96.56961

Ashley, C., \& Leonard, H. A. (2009). Betrayed by the buzz? Covert content and consumer-brand relationships. Journal of Public Policy \& Marketing, 28(2), 212-220. https://doi.org/10.1509/jppm.28.2.212

Blackwell, R. D., Miniard, P. W., \& Engel, J. F. (2001). Consumer behavior 9th. South-Western Thomas Learning. Mason, $\mathrm{OH}$.

Bloch, P. H. (1995). Seeking the ideal form: product design and consumer response. Journal of Marketing, 59(3), 16-29. https://doi.org/10.1177/002224299505900302

Chang, Y. P., \& Zhu, D. H. (2012). The role of perceived social capital and flow experience in building users' continuance intention to social networking sites in China. Computers in Human Behavior, 28(3), 995-1001. https://doi.org/10.1016/j.chb.2012.01.001

Chechen, L., Hong-Nan, L., Margaret, M. L., \& Sophea, C. (2016),” Factors influencing online shoppers' repurchase intentions: The roles of satisfaction and regret". Information \& Management Available online, December 2016, In Press, Corrected Proof - Note to users.

Faryabi, M., Karami, A., \& Rezaiee, S. (2011). "The effect of brand perceived value on customer re-purchase intention", Master thesis, Tabriz University.

Faryabi, M., Senobar, N., \& Maleki, A. S. (2017). "The Effect of Service Quality on Repurchase Intention and Good Sense of Customers with Mediating Role of Relationship Quality ", Master's thesis, Tabriz University.

Filieri, R., \& Lin, Z. (2017). The role of aesthetic, cultural, utilitarian and branding factors in young Chinese consumers' repurchase intention of smartphone brands. Computers in Human Behavior, 67, 139-150. https://doi.org/10.1016/j.chb.2016.09.057

Ha, H. Y., Muthaly, S. K., \& Akamavi, R. K. (2010). Alternative explanations of online repurchasing behavioral intentions: A comparison study of Korean and UK young customers. European Journal of Marketing, 44(6), 874-904. https://doi.org/10.1108/03090561011032757

Jalali, S. M., Kheiri, B., \& Khadem, M. (2011). "Investigating the Factors Affecting Brand Loyalty and Repurchase Intention of Iranian Consumers (Case Study: Home Appliances)". Journal of Researcher (Management), 8(24).

Kim, D., Chun, H., \& Lee, H. (2014). Determining the factors that influence college,students' adoption of Smartphones. Journal of the Association for information, Science and Technology, 65(3), 578e588. https://doi.org/10.1002/asi.22987

Koo, C., Chung, N., \& Kim, H. W. (2015). Examining explorative and exploitative uses of smartphones: a user competence perspective. Information Technology \& People, 28(1), 133-162. https://doi.org/10.1108/ITP-04-2013-0063

Kuo, Y. F., Wu, C. M., \& Deng, W. J. (2009). The relationships among service quality, perceived value, customer satisfaction, and post-purchase intention in mobile value-added services. Computers in human behavior, 25(4), 887-896. https://doi.org/10.1016/j.chb.2009.03.003

Lai, F., Griffin, M., \& Babin, B. J. (2009). How quality, value, image, and satisfaction create.

Lee, M. C. (2010). Explaining and predicting users' continuance intention toward e-learning: An extension of the expectation-confirmation model. Computers \& Education, 54(2), 506-516. https://doi.org/10.1016/j.compedu.2009.09.002

Persaud, A., \& Azhar, I. (2012). Innovative mobile marketing via smartphones: are consumers ready? Marketing Intelligence \& Planning, 30(4), 418-443. https://doi.org/10.1108/02634501211231883

Qian, S. U., Peiji, S. H. A. O., \& Quanfu, Y. E. (2011). An integrated analysis framework for customer value, customer satisfactory, switching barriers, repurchase intention and attitudinal loyalty: Evidences from China mobile data services. Management Science and Engineering, 5(3), 135-142.

Quintal, V. A., \& Polczynski, A. (2010). Factors influencing tourists' revisit intentions. Asia Pacific Journal of Marketing and Logistics, 22(4), 554-578. https://doi.org/10.1108/13555851011090565

Raffaele, F., \& Lin, Z. B. (2016). The role of aesthetic, cultural, utilitarian and branding factors in young Chinese consumers' repurchase intention of smartphone brands. Computers in Human Behavior, 1-12.

Ranjbarian, B. (2012). "Analysis of the relationship between perceived value, perceived quality, customer satisfaction and repurchase intention in Tehran's chain stores." Commercial Management, 1(11), 6. 
Schoefer, K., \& Diamantopoulos, A. (2008). The role of emotions in translating perceptions of (in) justice into postcomplaint behavioral responses. Journal of Service Research, 11(1), 91-103. https://doi.org/10.1177/1094670508319091

Teimourpour, B., \& Heidarzadeh, H. K. (2011). "The impact of culture on luxury consumption behaviour among Iranian consumers". Journal of Islamic Marketing, 2(3), 309-328. https://doi.org/10.1108/17590831111164822

Wang, W. T., \& Li, H. M. (2012). Factors influencing mobile services adoption: a brand- equity perspective. Internet Research, 22(2), 142-179. https://doi.org/10.1108/10662241211214548

\section{Copyrights}

Copyright for this article is retained by the author(s), with first publication rights granted to the journal.

This is an open-access article distributed under the terms and conditions of the Creative Commons Attribution license (http://creativecommons.org/licenses/by/4.0/). 